九州大学学術情報リポジトリ

Kyushu University Institutional Repository

\title{
An Experimental Study of Intraspecific Competition in Two Parasitoids of Comstock Mealybug
}

Murakami, Yozo

Division of Insect Natural Enemies, Institute of Biological Control, Faculty of Agriculture, Kyushu University

https://doi.org/10.5109/22885

出版情報：九州大学大学院農学研究院紀要. 20 (1)，pp. 15-25，1975-10. Kyushu University バージョン：

権利関係 : 


\title{
An Experimental Study of Intraspecific Competition in Two Parasitoids of Comstock Mealybug
}

\author{
Yôzô M urakami \\ Division of Insect Natural Enemies, Institute of \\ Biological Control, Faculty of Agriculture, \\ Kyushu University, Fukuoka
}

(Received July 17, 1975)

\begin{abstract}
Experiments on the process of intraspecific competition in two parasitoids of Comstock mealybug were performed under controlled laboratory conditions which led to the phenomenon of superparasitism. The process to eliminate supernumeraries is strikingly dissimilar between Clausenia purpurea and Pseudaphycus malinus. The former, a solitary parasitoid, kills excess individuals by physiological suppression in the early stage of development, whereas the latter, a gregarious parasitoid, eliminates others through selective starvation in the older stages. The typical processes of elimination of excess parasitoids in solitary forms are deliberate physical attack and physiological suppression in their early stages, whereas in gregarious forms it takes place typically by selective starvation or asphyxiation in the older stages. These processes seem to be characters which have been developed adaptively in relation to the phases of solitary and gregarious parasitism.
\end{abstract}

\section{INTRODUCTION}

When an individual host is attacked by more parasitoids of the same species than can develop upon it, it results in the phenomenon of superparasitism. In such hosts intraspecific competition occurs between immature parasitoids. Some hymenopterous parasitoids deliberately seek to avoid such competition among their progeny when laying their eggs. Even in such parasitoids, however, under certain circumstances when healthy hosts are scarce, they will lay eggs in hosts that are already parasitized. The present paper deals with experiments on the process of intraspecific competition in hosts when held under controlled laboratory conditions leads to the phenomenon of superparasitism in two species of parasitoids.

\section{MATERIAL AND METHODS}

These experiments were performed in 1968. Two species of encyrtid parasitoids which attack the Comstock mealybug, Pseudococcus comstocki (Kuwana) were selected : Clausenia purpurea Ishii and Pseudaphycus malinus Gahan. The biology of both parasitoids is well known. Clausenia is a solitary parasitoid which attacks only the first- and second-stage nymphs of the mealybug, whereas Pseudaphycus is a gregarious species which parasitizes not only every nymphal stage but also the adult female. During a single host generation, the former has 
only one generation whereas the latter two generations (Murakami, 1966).

The stock of Clausenia used in the experiments was bred from several individuals taken from a pear orchard at Hiratsuka, Kanagawa Prefecture and that of Pseudaphycus was obtained from an orchard at Ryugrji, Fukuoka City.

The host mealybug was reared on Japanese squash. To expose the hosts to a parasitoid. infested squash was placed in a slecve cage with a glass top and cloth panelling at the rear $(250 \mathrm{~mm}$ x250 mmx225 mm) which contained an enormous number of adult parasitoids for two or three days (Figs. 1 and 2).

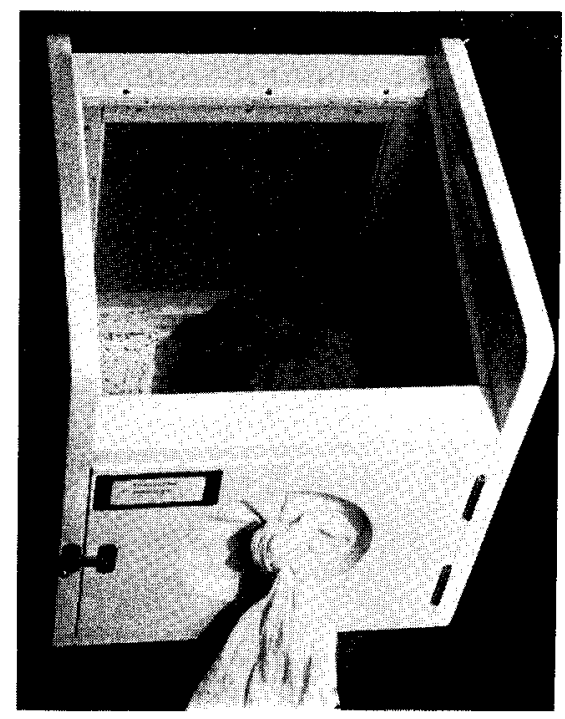

Fig. 1. View of a sleeve cage containing a number of adult Clausenia, in which mealybugs on a squash were exposed to attack for few days.

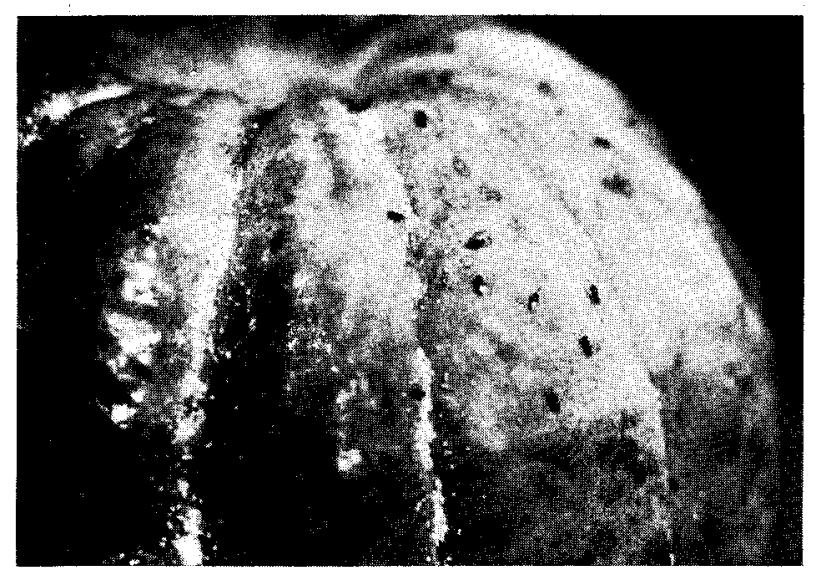

Fig. 2. Young nymphs of mealybug exposed to attack of Clausenia on a squash in a cage. 
The cage was placed in an insectary kept under constant of approximately $25^{\circ} \mathrm{C}$. The hosts were then examined by dissecting at intervals of three days in most cases, and the number of pre-imaginal parasitoids and their developmental stage within each host were recorded. Approximately 100 individuals of the hosts were dissected in each examination. Specific methods will be described later as the necessity arises.

\section{RESULTS}

\section{Clausenia purpurea}

The first- and second-stage mealybug nymphs 6 to 9 days old reared on squash were exposed to the attack of the parasitoids for three days from July 29 to August 1. To examine the rate of superparasitization and the sequential occurrence of elimination of the excess parasitoids, the hosts were dissected on August 3, 6, 9, 12 and 15 .

Results of the experiment are shown in Tables 1 and 2 . It often occurred that more than one egg of the parasitoid were laid in a single host; and in this case, all the individuals other than one must die since only one Clausenia can develop in each host. Of 45 parasitized host in the first examination (Aug. 3), 22 nymphs or $49 \%$ had been parasitized by only one parasitoid whereas 23 nymphs or $51 \%$ were found with two or more individuals of the parasitoid. The average number of supernumeraries per host parasitized was calculated to be 0.78 because the average number of parasitoids in a single host was 1.78 and all the individuals other than one parasitoid within each host were supernumeraries (Table 1). Of the 22 nymphs containing only one parasitoid, 17 hosts were harbouring parasitoid eggs and other 5 hosts were harbouring first-stage larvae. With the 23 hosts parasitized by two or more individual parasitoids, 18 hosts were harbouring only parasitoid eggs (14 hosts with two eggs, 1 host with three eggs and 3 hosts with four eggs), 2 hosts were harbouring only first-stage

Table 1. Results of an experiment of intraspecific competition in Clausenia purpurea. The host mealybugs were exposed to the attack of the parasitoids during Jul. 29 - Aug. 1.

\begin{tabular}{|c|c|c|c|c|c|c|c|c|c|}
\hline \multirow[t]{2}{*}{$\begin{array}{l}\text { Exam- } \\
\text { ination }\end{array}$} & \multirow[t]{2}{*}{$\begin{array}{l}\text { Date of } \\
\text { dissection }\end{array}$} & \multirow{2}{*}{$\begin{array}{c}\text { No. of } \\
\text { parasitized } \\
\text { hosts } \\
\text { examined }\end{array}$} & \multicolumn{5}{|c|}{$\begin{array}{l}\text { Frequency distribution of no. } \\
\text { of parasitoids in a } \\
\text { single individual host }\end{array}$} & \multirow{2}{*}{$\begin{array}{c}\text { Average } \\
\text { no. of } \\
\text { para- } \\
\text { sitoids } \\
\text { per host }\end{array}$} & \multirow{2}{*}{$\begin{array}{c}\text { Average } \\
\text { no. of } \\
\text { supernu- } \\
\text { meraries }\end{array}$} \\
\hline & & & 1 & 2 & 3 & 4 & 5 & & \\
\hline 1 & Aug. 3 & 45 & $\begin{array}{c}22 \\
(49 \%)\end{array}$ & ( & $\begin{array}{l}3 \\
6 \\
6\end{array}$ & $\begin{array}{c}3 \\
\left(\begin{array}{l}1 \\
1\end{array}\right.\end{array}$ & $\left(\begin{array}{c}1 \\
2 \%\end{array}\right.$ & 1.78 & 0.78 \\
\hline 2 & Aug. 6 & 62 & $(7446 \%)$ & $(15 \%)$ & $(10 \%)$ & $c^{296)}$ & 0 & 1.39 & 0.39 \\
\hline 3 & Aug. 9 & 60 & $\left(\frac{57}{71^{m 1}}\right)$ & \begin{tabular}{c}
3 \\
\hdashline 1
\end{tabular} & 0 & 0 & 0 & 1.05 & 0.05 \\
\hline 4 & Aug. 12 & $7 \%$ & $(99 \%)$ & $c^{196)}$ & 0 & 0 & 0 & 1.01 & 0.01 \\
\hline 5 & Aug. 15 & 57 & $\begin{array}{c}57 \\
(100 \%)\end{array}$ & 0 & 0 & 0 & 0 & 1 & 0 \\
\hline
\end{tabular}


larvae (one host with three larvae and another with five larvae) and 3 hosts were harbouring both eggs and larvae (2 hosts with one egg and one larva, and another host with two eggs and one larva). Therefore, the percentages of the parasitoid eggs and larvae to the total number of parasitoids were $77.3 \%$ and $22.7 \%$ in hosts containing only one parasitoid, whereas $81.0 \%$ and $19.0 \%$ were found in those with two or more parasitoids, respectively (Table 2).

Table 2. Age structure of Clausenia within hosts at each examination.

\begin{tabular}{|c|c|c|c|c|c|c|}
\hline \multirow{2}{*}{ Examination } & \multicolumn{3}{|c|}{$\begin{array}{l}\text { Within hosts containing } \\
\text { a single individual } \\
\text { of the parasitoid }\end{array}$} & \multicolumn{3}{|c|}{$\begin{array}{l}\text { Within hosts containing } \\
\text { two or more individuals } \\
\text { of the parasitoid }\end{array}$} \\
\hline & Egg & $\begin{array}{l}\text { lst-stage } \\
\text { larva }\end{array}$ & $\begin{array}{c}\text { 2nd-stage } \\
\text { larva }\end{array}$ & Egg & $\begin{array}{l}\text { 1st-stage } \\
\text { larva }\end{array}$ & $\begin{array}{c}\text { 2nd-stage } \\
\text { larva }\end{array}$ \\
\hline 1 & $\begin{array}{c}17 \\
(77.3 \%)\end{array}$ & $\begin{array}{c}5 \\
(22.7 \%)\end{array}$ & 0 & $\begin{array}{c}47 \\
(81.0 \%)\end{array}$ & $\begin{array}{c}11 \\
(19.0 \%)\end{array}$ & 0 \\
\hline 2 & (6. $5 \%)$ & \multicolumn{2}{|c|}{$\begin{array}{c}43 \\
(93.5 \%)\end{array}$} & $\begin{array}{c}10 \\
(25.0 \%)\end{array}$ & \multicolumn{2}{|c|}{$\begin{array}{c}30 \\
(75.0 \%)\end{array}$} \\
\hline 3 & $(3.5 \%)$ & \multicolumn{2}{|c|}{$\begin{array}{c}55 \\
(96.5 \%)\end{array}$} & $\begin{array}{c}6 \\
-1 n\end{array}$ & 0 & 0 \\
\hline 4 & U & 0 & $\begin{array}{c}71 \\
(100 \%)\end{array}$ & $(100$ & 0 & 0 \\
\hline 5 & $c^{116 \%)}$ & 0 & $\begin{array}{c}56 \\
(98.2 \%)\end{array}$ & - & - & - \\
\hline
\end{tabular}

With the result of the second examination (Aug. 6), it was found that 46 nymphs or $74 \%$ of 62 hosts parasitized contained only one parasitoid, whereas 16 nymphs or $26 \%$ had two or more parasitoids. The supernumeraries per host decreased to 0.39 (Table 1). This means that approximately $50 \%$ of supernumeraries which had existed in hosts three days ago were eliminated by competition during this period. Of the 46 hosts harbouring only one parasitoid, 3 hosts contained parasitoid eggs and 43 hosts had first- or second-stage larvae of the parasitoid; therefore, the percentages of the eggs and larvae to the total parasitoids were $6.5 \%$ and $93.5 \%$, respectively. The 16 hosts which were harbouring two or more individuals of the parasitoid consisted of 2 hosts containing only eggs of the parasitoid (one with two eggs and another with three eggs), 12 others with only first- or second-stage larvae of the parasitoid ( 8 hosts with two larvac and 4 hosts with three larvae) and 2 mealybugs with both eggs and larvae (one with two eggs and one larva, and another with three eggs and one larva) ; therefore, the percentages of the eggs and larvae to the total parasitoids were $25.0 \%$ and $75.0 \%$ (Table 2).

The result of the third examination (Aug. 9) shows that 57 host individuals or $95 \%$ of 60 hosts parasitized contained only one parasitoid, whereas 3 hosts or $5 \%$ had two parasitoids. The supernumeraries per host decreased further to 0.05 (Table 1). It is, therefore, suggested that the $94 \%$ of the excess parasitoids which had existed six days earlier were eliminated by competition during this period of six days. With the $57 \mathrm{~h}$ osts containing one parasitoid, eggs of the parasitoid were recognized only in 2 hosts and the other 55 hosts were 
harbouring first- or second-stage larvae ; therefore, the percentages of the eggs and larvae to the total parasitoids were $3.5 \%$ and $96.5 \%$. In the 3 cases where two parasitoids were found in a single host, all the parasitoids were in the egg stage (Table 2).

On the day of the fourth examination (Aug. 12), only one host among 72 hosts parasitized, had two eggs of the parasitoid, and the other hosts contained only one individual of second-stage larva of the parasitoid. The supernumeraries per host were 0.01 , therefore, almost $99 \%$ of the excess at the first examination were eliminated during nine days (Tables 1 and 2). At the final examination (Aug. 15), all 57 hosts parasitized contained only one parasitoid. The elimination of the excess parasitoids was completed. Most of the parasitoids were in the second larval stage except one egg (Tables 1 and 2).

It is concluded from the results mentioned above that when an individual host is parasitized by two or more Clausenia the elimination of the excess parasitoids seems to take place in the first larval stage. The age structure of the parasitoids within the hosts at each examination revealed the difference in changes of the structure between parasitoids within hosts containing a single individual of the parasitoid and two or more parasitoids (Table 2). At the first examination the percentages of the parasitoid larvae were almost equal in both cases. After the second examination, however, lower percentages of the larvae were observed in hosts containing two or more parasitoids than in those containing a single one. Especially at the third and fourth examinations any parasitoid larvae were not observed in hosts harbouring two or more parasitoids when the majority of parasitoids were first- or second-stage larvae in hosts containing a single parasitoid. This fact suggests that competition between parasitoids in the superparasitized hosts occurs in the early larval stages, perhaps in the first larval stage. The larvae in this stage, however, are without any powerful mandibles, and observations show neither physical combat between parasitoids nor mutual starvation taking place through the course of dissection. On the other hand, the remains of the destroyed larvae did not persist.

\section{Pseudaphycus malinus}

Adult mealybug females 20 to 22 days old were exposed to the attack of Pseudaphycus for two days from August 5 to 7 . Dissection of the mealybugs was made on August 8, 11, 14, 16 and 20. Results are shown in Tables 3 and 4. Since Pseudaphycus is a gregarious parasitoid as mentioned before and the individual number of parasitoids which can develop upon a single individual host varies with the size of the host, it is impossible previously to know what is the critical number of parasitoids which can survive in a single host in the case of this experiment. When an individual host is parasitized by a number of Pseudaphycus more than the critical number, the phenomenon of superparasitism will take place.

The host mealybug dies when the parasitoids grow into mature larvae in their host. At this time competition between parasitoids is completed within the host. The critical number of parasitoids on the average which can survive in a single host may be represented by the mean number of actual parasitoids 
observed in the dead or mummified hosts. In this experiment, the dead hosts were recognized at the third (41 mummies), fourth (56 mummies) and final (60 mummies) examinations. The mean number of surviving parasitoids observed in these 157 hosts was 15.2 per host (Table 3). It was, therefore, concluded that the parasitoids other than 15.2 individuals on the average in a single host must have died in this experimental population, so that the critical number of parasitoids which could survive in a single host was believed to be 15.2 in this experiment.

Table 3. Results of an experiment of intraspecific competition in Pseudaphycus malinus. The host mealybugs were exposed to the attack of the parasitoids during Aug. 5-7.

\begin{tabular}{|c|c|c|c|c|c|c|c|c|c|c|c|c|}
\hline \multirow{3}{*}{$\begin{array}{c}\text { Exam- } \\
\text { ina- } \\
\text { tion }\end{array}$} & \multirow{3}{*}{$\begin{array}{l}\text { Date of } \\
\text { dissec- } \\
\text { tion }\end{array}$} & \multicolumn{10}{|c|}{$\begin{array}{l}\text { No. of parasitized hosts examined }(\mathrm{H}) \text { and average no. of } \\
\text { parasitoids (P) within hosts which were classified into four } \\
\text { categories" (A-D) according to developmental stages of } \\
\text { parasitoids }\end{array}$} & \multirow{3}{*}{$\begin{array}{l}\text { Average } \\
\text { no. of } \\
\text { supernu- } \\
\text { meraries }\end{array}$} \\
\hline & & \multicolumn{2}{|c|}{ A } & \multicolumn{2}{|c|}{ B } & \multicolumn{2}{|c|}{ C } & \multicolumn{2}{|c|}{ D } & \multicolumn{2}{|c|}{ Total } & \\
\hline & & $\mathrm{H}$ & $\mathrm{P}$ & $\mathrm{H}$ & $\mathrm{P}$ & $\mathrm{H}$ & $\mathrm{P}$ & $\mathrm{H}$ & $\mathrm{P}$ & $\mathrm{H}$ & $\mathrm{P}$ & \\
\hline 1 & Aug. 8 & 84 & 38.6 & 0 & - & 0 & - & 0 & - & 84 & 38.6 & $(48.0)^{2)}$ \\
\hline 2 & Aug. 11 & $\begin{array}{c}46 \\
(62.2 \%\end{array}$ & 65.6 & 18 & 57.3 & 10 & 58.0 & 0 & - & 74 & 62.5 & 47.3 \\
\hline 3 & Aug. 14 & $(10.0 \%$ & 6) 57.9 & $\begin{array}{l}(24.3 \% \\
24\end{array}$ & 60.0 & $\begin{array}{c}(13.5 \% \\
16\end{array}$ & 33.6 & 41 & 13.8 & 90 & 34.0 & 18.8 \\
\hline 4 & Aug. 16 & 4 & 48.3 & $\stackrel{(26279}{(}$ & 38.5 & $\begin{array}{c}(17.8 \% \\
8\end{array}$ & 32.0 & $\begin{array}{c}(45.6 \%) \\
56\end{array}$ & 15.5 & 70 & 19.9 & 4.7 \\
\hline 5 & Aug. 20 & $5.67 \%$ & \%) - & $\begin{array}{c}2.99 \\
0\end{array}$ & - & $\begin{array}{l}(11.4 \%) \\
(\quad 4.8 \%\end{array}$ & 4.0 & $\begin{array}{l}(80.0 \%) \\
(950.2 \%)\end{array}$ & 15.9 & 63 & 15.3 & 0.1 \\
\hline
\end{tabular}

Total or average of the data from 2nd to 5th exam59 63.2
$(\mathrm{~L}-10.6)$ $44 \begin{gathered}57.9 \\ ( \pm 11.7)\end{gathered}$ $37 \quad 37.5 \quad 157$ $(\mathrm{t} 12.6)$ 15.2
$( \pm 1.0)$ inations

1) "A" refers hosts containing eggs and / or lst-stage larvae without more progressive stage parasitoids, "B" refers those containing 2nd-stage larvae without more progressive stage parasitoids, "C" refers those containing 3rd- and / or 4th-stage larvae without more progressive stage parasitoids and " $D$ " refers dead and mummified hosts containing mature larvae, prepupae and / or pupae of parasitoids.

2) Average number of supernumeraries in the 1st examination is an estimated figure discussed in text.

The results of the first and second examinations (Aug. 8 and 11) show that the mean numbers of parasitoid individuals per host were 38.6 and 62.5, respectively (Table 3). It is impossible for the number of parasitoids per host to increase, as shown in this datum. It indicates, therefore, that the observed number during the first examination was less than the second which was probably due to a miscount since all the parasitoids were in the egg stage at the first examination. A more feasible estimate will be discussed later.

At the second examination the average number of the supernumeraries per host parasitized was calculated to be 47.3 because the mean number of parasitoids in a single host was 62.5 and the individuals other than 15.2 within each host 
may be the excess. Of 74 hosts parasitized, 46 contained only eggs, both eggs and first-stage larvae, or only first-stage larvae of the parasitoid (category " $\mathrm{A}$ " in Table 3). The mean number of parasitoids within these hosts was 65.6 per host. Of the remaining 28 mealybugs parasitized, 18 contained second-stage larvae but did not include third or more progressive stage larvae of the parasitoid (category "B" in Table 3), and the average number of parasitoids within these hosts was 57.3 per host. The 10 remaining individual hosts harboured the thirdand/ or fourth-stage larvae of the parasitoid (category "C" in Table 3), and the mean number of parasitoids was 58.0 per host in this case (Table 3). At this time 438 individuals or $9.4 \%$ of the total parasitoids within the hosts were in the egg stage, and 4,190 individuals or $90.6 \%$ were in the first to third larval stages (Table 4).

Table 4. Age structure of Pseudaphycus malinus within hosts at each examination.

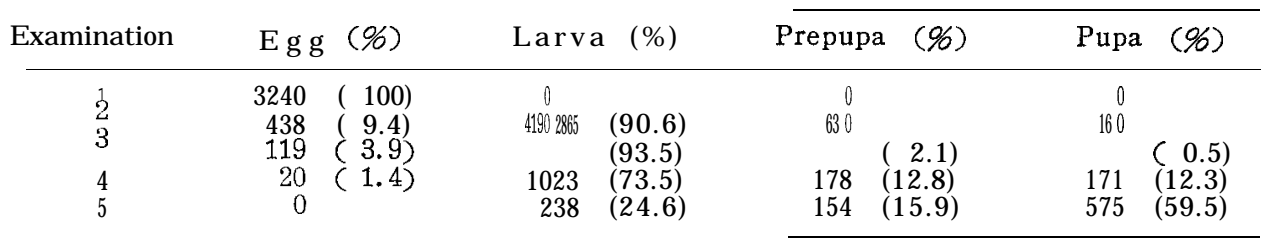

With the result of the third examination (Aug. 14), it was found that the average number of parasitoid individuals per host was 34.0, so that the living supernumeraries per host decreased to 18.8 or approximately $40 \%$ of those at the second examination (Table 3). Of 90 mealybugs parasitized, 9 hosts were harbouring either both eggs and first-stage larvae of the parasitoid or only the latter (category "A" in Table 3). The average number of parasitoids within these host were 57.9 per host. Of the remaining 81 hosts parasitized 24 were found to contain second-stage larvae of parasitoids, but not third- or more progressive stages (category "B" in Table 3), and the mean number of parasitoids was 60.0 per host. The other 16 hosts included third- and/ or fourth-stage larvae of parasitoids, but no additional progressive stages (category " $\mathrm{C}$ " in Table 3 ), the mean number of parasitoids being 33.6 per host. The remaining 41 mealybugs were harbouring fifth-stage larvae, prepupae and/or pupae of the parasitoid and these hosts had been killed (category " $D$ " in Table 3), the average number of parasitoids being 13.8 per host (Table 3). At this time 119 individuals or $3.9 \%$ of parasitoids within the hosts were in the egg stage, 2,865 individuals or $93.5 \%$ being in the larval, 63 individuals or $2.1 \%$ in the prepupal, and 16 individuals or $0.5 \%$ in the pupal stages (Table 4).

The average number of living parasitoids within the hosts decreased to 19.9 in the fourth examination (Aug. 16) as shown in Table 3, and the surviving supernumeraries were calculated to be only 4.7 per host parasitized, approximately $10 \%$ of those at the second examination. During the period of two days after the third examination, the parasitoids developed so rapidly that most were in the mature larval, prepupal or pupal stages, causing a severe elimination of the excess parasitoids. Out of 70 hosts parasitized, 14 mealybugs were living, and harboured only fourth- or younger larval stages of parasitoids. The average 
number of parasitoids within these hosts was 37.6. The other 56 mealybugs or $80 \%$ of the total hosts parasitized contained mature larvae, prepupae and/or pupae of the parasitoid. The mean number of the surviving parasitoids was 15.5 per host (Table 3). At this time 20 individuals or $1.4 \%$ of the parasitoids were in the egg stage, 1,023 individuals or $73.5 \%$ in the larval, 178 individuals or $12.8 \%$ in the prepupal, and 171 individuals or $12.3 \%$ in the pupal stages (Table 4).

At the final examination (Aug. 20), the elimination of excess parasitoids was almost completed as shown in Table 3, i.e., the average number of parasitoids being 15.3 per host. Of 63 hosts parasitized only 3 mealybugs were living which contained third- and fourth-stage larvae of the parasitoid, whereas 60 hosts were already killed and mummified which were harbouring mature larvae, prepupae and/ or pupae of the parasitoid (Table 3). At this time 238 individuals or $24.5 \%$ of the parasitoids were in the fourth and fifth (mature) larval stages, 154 individuals or $15.9 \%$ in the prepupal, 575 individuals or $59.5 \%$ in the pupal stages (Table 4).

In order to determine when the excess of parasitoids were eliminated, the mean numbers of parasitoids in a single host were calculated with the developmental stages of parasitoids within hosts from the data except in the first examination as shown at the bottom line in Table 3 . Within the hosts harbouring only eggs, both eggs and first-stage larvae, or only first-stage larvae of the parasitoid (category " $\mathrm{A}$ "), the mean number of parasitoids was 63.2 per host. With the hosts in which parasitoids developed to the second-stage larvae (category "B"), the mean number of parasitoids was 57.9 , the value decreasing slightly, but not significantly. The elimination of the supernumeraries seems to have taken place mainly in older stages rather than the third larval stage, because the mean number of parasitoids per host decreased to 37.5 in hosts harbouring third- and/or fourth-stage larvae without more progressive stages (category "C"), and to 15.2 in dead and mummified hosts which contained mature larvae, prepupae and / or pupae of the parasitoid (category "D"). The competition may take place through mutual starvation.

As already mentioned, the average number of parasitoids per host observed in the first examination was less than the second due to a miscount. Since competition would scarcely take place during the period that the parasitoids are in the egg and first larval stages, the mean number of parasitoids within the hosts of category " $A$ " in the second to fourth examinations could represent the possible estimate at the first examination in which all the parasitoids within hosts were in the egg stage. Therefore, the average number of the supernumeraries is estimated to be 48.0 .

\section{DISCUSSION}

Salt (1961) suggested four processes whereby supernumerary parasitoids might be eliminated :(1) deliberate physical attack, (2) physiological suppression, (3) accidental injury, and (4) selective starvation. He listed 20 species of solitary internal parasitoids that had been observed fighting or said to eliminate 
competitors by physical attack. In all cases except one, the stage of the fighting larvae was the first-stage. They have sickle-shaped mandibles. According to his own observation with Venturia $(=$ Nemeritis) canescens (Grevenhorst), the fighting took place soon after the larvae hatch.

Since Timberlake (1910) first observed the phenomenon of the elimination of supernumerary parasitoids in aphidiine larvae by a physiological process, a number of species of parasitoid Hymenoptera have been recorded displaying physiological suppression of competitors. Timber-lake concluded that supernumeraries were killed by a secretion from an older larva present in the same host. Similar cases have been observed with Aphidius sp. (bio-chemical process of inhibition of younger larvae by older ones) by Spencer (1926), with Comperiella bifasciata Howard (some unknown factor which is also inhibitory to the survivor) by Compere and Smith (1927), with Eulimneriacrassifemur (Thomson) (a cytolytic enzyme) by Thompson and Parker (1930), with Coccophagus gurneyi Compere (some process which appears very similar to the so-called 'phagocytic action') by Compere and Smith (1932), with Coccophagus scutellaris (Dalman) (host resistance) by Cendaña (1937), with Microctonus vittatae Muesebeck (some chemical agent secreted by the first larva that hatches) by Smith (1952), with Aphidius platensis Brèthes (chemical means) by Johnson (1959), and with several other parasitoids by other authors. Several possible explanations for the mechanism of the physiological suppression have been put forward. Fisher (1961) made experiments of multiparasitism using Venturia canescens and Horogenes chrysostictos Gmelin. He suggested that asphyxiation by oxygen-lack could better account for physiological suppression than the theories of toxic secretion, specific inhibition and starvation. Salt (1961) supported Fisher's explanation and criticized the interpretations by several authors who had invoked a toxic secretion or cytolytic enzyme to explain the death of supernumerary parasitoid larvae.

All parasitoids cited above in which physiological suppression has been observed are solitary ones except Coccophagus scutellasis which is a gregarious parasitoid. The supernumeraries of these solitary parasitoids died in the egg stage, in the first larval stage very soon after hatching, or at most in the secondstage. A quick decision of the doom of the competition in solitary parasitoids both in the cases of physical attack and physiological suppression is an advantage to the parasitoids as stated by Salt (1961). If the death would not take place early, the food taken by the excess larvae would be wasted.

In contrast with solitary parasitoids, supernumerary larvae of gregarious parasitoids are not necessarily eliminated at an early stage. Most gregarious parasitoid larvae do not fight each other in the same host. But in a rare case, accidental injury has been observed. With a polyembryonic parasitoid, Macrocentrus gifuensis Ashmead, some embryos are destroyed at the moment of hatching by the earlier unfolding larvae. If the larva unfolds in such a way that there is an embryo near its mandibles, that embryo is killed by the chewing of the unfolded larva (Parker, 1931). This is a case of accidental injury, the third category of elimination processes of supernumeraries suggested by Salt. Except for this case, supernumerary larvae of gregarious parasitoids persist until they are nearly full grown. The elimination may be due to shortage of food and/ or 
possibly of oxygen.

In the case of the present experiments the process to eliminate supernumeraries is strikingly dissimilar between Clausenia and Pseudaphycus. The former, a solitary parasitoid, kills the excess by physiological suppression in the early stage, whereas the latter, a gregarious parasitoid, kills through selective starvation in the older stages. Table 5 shows the survival rates of supernumeraries of Clausenia and Pseudaphycus in the present experiments of which the rates in the first examination were calculated to be $100 \%$. From these results the elimination of supernumeraries of both parasitoids was shown schematically in Fig. 3.

Table 5. Survival rate of supernumeraries of Clausenia and Pseudaphycus in the present experiments.

\begin{tabular}{|c|c|c|c|c|c|c|}
\hline & & & & & & \\
\hline \multirow[b]{2}{*}{ Examination } & \multicolumn{3}{|c|}{ Clausenia purpurea } & \multicolumn{3}{|c|}{ Pseudaphycus malinus } \\
\hline & $\begin{array}{l}\text { Period from } \\
\text { egg-laying } \\
\text { to dissection } \\
\text { (days) }\end{array}$ & $\begin{array}{l}\text { Dominant } \\
\text { stages of } \\
\text { parasiloids }\end{array}$ & $\begin{array}{l}\text { Survival } \\
\text { rate of } \\
\text { supernumer- } \\
\text { aries }(\%)\end{array}$ & $\begin{array}{l}\text { Period from } \\
\text { egg-laying } \\
\text { to dissection } \\
\text { (days) }\end{array}$ & $\begin{array}{l}\text { Dominant } \\
\text { stages of } \\
\text { parasitoids }\end{array}$ & $\begin{array}{l}\text { Survival } \\
\text { rate of } \\
\text { supernumer- } \\
\text { aries }(\%)\end{array}$ \\
\hline \multirow{3}{*}{2} & $2 \sim 5$ & $\begin{array}{l}\text { Egg and } \\
\text { 1st larval } \\
\text { stages }\end{array}$ & 100 & $1 \sim 3$ & Egg stage & 100 \\
\hline & $5 \sim 8$ & $\begin{array}{l}\text { 1st and 2nd } \\
\text { larval } \\
\text { stages }\end{array}$ & 50 & $4 \sim 6$ & $\begin{array}{l}\text { 1st to 3rd } \\
\text { larval } \\
\text { stages }\end{array}$ & 99 \\
\hline & 8- 11 & $\begin{array}{l}\text { 2nd larval } \\
\text { stage }\end{array}$ & 6 & $7 \sim 9$ & $\begin{array}{l}\text { 3rd to 5th } \\
\text { larval } \\
\text { stages }\end{array}$ & 39 \\
\hline 4 & $11-14$ & $\begin{array}{l}\text { 2nd larval } \\
\text { stage }\end{array}$ & 1 & $9-11$ & $\begin{array}{l}\text { 4th and 5th } \\
\text { larval } \\
\text { stages }\end{array}$ & 10 \\
\hline 5 & $14 \sim 17$ & $\begin{array}{l}\text { 2nd larval } \\
\text { stage }\end{array}$ & 0 & $13 \sim 15$ & Pupal stage & 0.2 \\
\hline
\end{tabular}

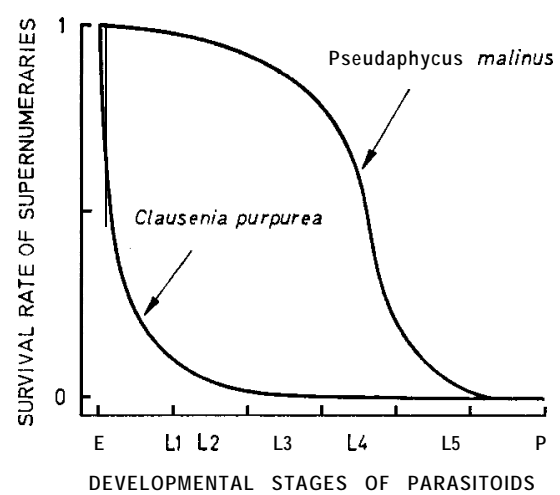

Fig. 3. Elimination of the excess individuals of Clausenia and Pseudaphycus through intraspecific competition within hosts. $E$, egg stage; $L_{1}-L_{,}$, first to fifth larval stages; $P$, pupal stage. 
The typical processes of elimination of excess individuals in solitary parasitoids are deliberate physical attack and physiological suppression in their early stages, whereas in gregarious forms the elimination takes place typically by selective starvation or asphyxiation in the older stages. These processes seem to be characters which have been developed adaptively in relation to the phases of solitary and gregarious parasitism. For solitary parasitoids, the elimination in early stages has been developed as a strategy to survive safely in a limited nutrition within the host avoiding waste. In gregarious parasitoids, the elimination in older stages is beneficial by realizing the production of more progeny in a host relatively large in size compared with the parasitoids.

\section{ACKNOWLEDGEMENT}

I wish to express my gratitude to Dr. D. E. Meyerdirk, University of California, for his kindness in reading through this manuscript.

\section{REFERENCES}

Cendaña, S. M. 1937 Studies on the biology of Coccophagus (Hymenoptera) a genus parasitic on nondiaspidine Coccidae. Univ. Calif.Publ. Ent., 6: 337-399, 1 pl.

Compere, H. and H. S. Smith 1927 Notes on the life-history of two oriental chalcidoid parasites of Chrysomphalus. Univ. Calif.Publ. Ent., 4: 63-73

Compere, H. and H. S, Smith 1932 The control of the citrophilus mealybug, Pseudococcus gahani, by Australian parasites. Hilgardia, 6: 585-618

Fisher, R. C. 1961 A study in insect multiparasitism II. The mechanism and control of competition for possession of the host. J. Exp. Biol., 38: 605-628, 1 pl. •

Johnson, B. 1959 Effect of parasitization by Aphidius platensis Brèthes on the developmental physiology of its host, Aphis craccivora Koch. Em. Exp. Appl., 2: 82-99

Murakami, Y. 1966 Studies on the natural enemies of the Comstock mealybug II. Comparative biology on two species of internal parasites, Clausenia purpurea and Pseudaphycus malinus (Hymenoptera, Encyrtidae). Bull. Hort. Res. Sta., Jap., Ser. A, 5: 139-162

Parker, H. L. 1931 Macrocentrus gifuensis Ashmead, polyembryonic braconid parasite in the European corn borer. Techn. Bull. USDA, 230: 1-62

Salt, G. 1961 Competition among insect parasitoids. Symp. Soc. Exp. Biol., 15: 96-119

Smith, 0. J. 1952 Biology and behavior of Microctonus vittatae Muesebeck (Braconidae). Univ. Calif. Publ. Ent., 9: 315-344

Spencer, H. 1926 Biology of the parasites and hyperparasites of aphids. Ann. Ent. Soc. Amer., $19: 119-157$

Thompson, W. R. and H. L. Parker 1930 The morphology and biology of Eulimneriacrassifemur, an important parasite of the European corn borer. J. Agr. Res., 40: 321-345

Timberlake, P. II. 1910 Observations on the early stages of two aphidiine parasites of aphids. Psyche, 17: 125-130 